\title{
Hypocapnia attenuates mesenteric ischemia-reper- fusion injury in a rat model
}

\section{[L’hypocapnie atténue la lésion mésentérique d'ischémie-reperfusion chez un modèle rat]}

\author{
Michelle Duggan MD, ${ }^{\star} \dagger \ddagger$ Doreen Engelberts, ${ }^{*}$ Robert P. Jankov MD, ${ }^{*} \$$ Jordan M. A. Worrall,, $\mathbb{I}$ Rong Qu MSc, $\mathbb{I}$ \\ Gregory M. T. Hare MD PhD, I A. Keith Tanswell MD, ${ }^{*} \mathbb{S}$ J. Brendan Mullen MD,\| Brian P. Kavanagh MD*†
}

Purpose: Hypocapnia, a recognized complication of high frequency oscillation ventilation, has multiple adverse effects on lung and brain physiology in vivo, including potentiation of free radical injury. We hypothesized that hypocapnia would potentiate the effects of mesenteric ischemia-reperfusion on bowel, liver and lung injury.

Methods: Anesthetized male Sprague-Dawley rats were ventilated with high frequency oscillation and were randomized to one of four groups, exposed to either mesenteric ischemia-reperfusion or sham surgery, and to either hypocapnia or normocapnia.

Results: All animals survived the protocol. Ischemia-reperfusion caused significant histologic bowel injury. Bowel 8-isoprostane generation was greater in ischemia-reperfusion vs sham, but was attenuated by hypocapnia. Laser-Doppler flow studies of bowel perfusion confirmed that hypocapnia attenuated reperfusion following ischemia. Plasma alanine transaminase, reflecting overall hepatocellular injury, was not increased by ischemia-reperfusion but was increased by hypocapnia; however, hepatic isoprostane generation was increased by ischemia-reperfusion, and not by hypocapnia. Oxygenation was comparable in all groups, and compliance was impaired by ischemia-reperfusion but not by hypocapnia.

Conclusion: Hypocapnia, although directly injurious to the liver, attenuates ischemia-reperfusion induced lipid peroxidation in the bowel, possibly through attenuation of blood flow during reperfusion.
Objectif : L'hypocapnie, complication reconnue de la ventilation par oscillation haute fréquence, a de multiples effets indésirables sur la physiologie pulmonaire et cérébrale in vivo, dont la potentialisation de lésion radicalaire. Nous avons émis l'hypothèse que l'hypocapnie augmenterait les effets d'une ischémie-reperfusion mésentérique sur une lésion de l'intestin, du foie et du poumon.

Méthode : Des rats mâles Sprague-Dawley anesthésiés, ventilés par oscillation haute fréquence, ont été randomisés en quatre groupes, exposés à une ischémie-reperfusion mésentérique ou à une intervention chirurgicale fictive et à l'hypocapnie ou à la normocapnie.

Résultats : Tous les animaux ont survécu. L'ischémie-reperfusion a causé une lésion histologique intestinale significative. La production intestinale de 8-isoprostane a été plus importante avec l'ischémiereperfusion vs l'opération fictive, mais atténuée par l'hypocapnie. Des études de la perfusion intestinale par laser-Doppler ont confirmé que l'hypocapnie avait diminué la reperfusion après l'ischémie. L'alanine transaminase plasmatique, traduisant la lésion hépatocellulaire globale, n'a pas été augmentée par l'ischémie-reperfusion, mais l'a été par l'hypocapnie ; toutefois, la production d'isoprostane hépatique s'est accrue avec l'ischémie-reperfusion, mais non avec l'hypocapnie. L'oxygénation était comparable dans tous les groupes et la compliance a été affectée par l'ischémie-reperfusion, mais non par l'hypocapnie.

Conclusion: L'hypocapnie, quoique directement nuisible au foie, diminue la peroxydation lipidique intestinale induite par l'ischémiereperfusion, probablement par diminution du débit sanguin pendant la reperfusion.

From the Lung Biology Program, ${ }^{*}$ The Research Institute and the Departments of Critical Care Medicine, $†$ Anaesthesia $\ddagger$ and Pediatrics, $\$$, The Hospital for Sick Children; the Department of Anesthesia, Cara Phelan Trauma Research Centre, I St. Michael's Hospital; and the Samuel Lunenfeld Research Institute, $\|$ Mount Sinai Hospital; Interdepartmental Division of Critical Care Medicine, University of Toronto, Toronto, Ontario, Canada.

Address correspondence to: Dr. Brian Kavanagh, Department of Critical Care Medicine, The Hospital for Sick Children, 555 University Avenue, Toronto, Ontario M5G 1X8, Canada. Phone: 416-813-6860; Fax: 416-813-5313; E-mail: brian.kavanagh@sickkids.ca Support: Canadian Institutes of Health Research (CIHR).

Dr. Kavanagh is the recipient of a New Investigator Award (CIHR), and a PREA award (Ontario Ministry of Science and Technology). Dr. Jankov is in receipt of fellowships from the Canadian Institute of Health Research and the Canadian Lung Association. Dr. Tanswell holds the Women's Auxillary Chair of Neonatology at the Hospital for Sick Children.

Accepted for publication August 26, 2004.

Revision accepted November 8, 2004. 


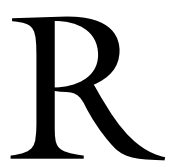

ECENT studies have demonstrated that high frequency oscillation (HFO) can be used safely and effectively to ventilate both pediatric ${ }^{1,2}$ and adult ${ }^{3}$ patients with respiratory failure. Although carbon dioxide can be easily monitored, ${ }^{4}$ hypocapnia is a recognized complication of $\mathrm{HFO}$ ventilation. ${ }^{5-8}$

Tissue ischemia, followed by vascular reperfusion, is an ubiquitous and serious element of many processes present in critical illness. ${ }^{9}$ The complex, referred to as 'ischemia-reperfusion' (IR) involves ischemic depletion of cellular energy sources and accumulation of free radical precursors; subsequent reperfusion - especially with high levels of circulating $\mathrm{O}_{2}$ - results therefore in a dual insult to a susceptible vascular bed. ${ }^{10,11}$ IR is therefore especially important, with immense practical applications, in the key vascular territories including brain, heart, lung, skeletal muscle and bowel. ${ }^{12}$ Mesenteric IR may be an especially relevant model in critical care, since intestinal mucosal ischemia and injury may initiate or propagate multiple organ dysfunctions via translocation of circulating bacterial products.

It is increasingly recognized that hypocapnia may have adverse effects on many clinical diseases. At a tissue level, hypocapnia may cause or aggravate cellular or tissue ischemia by both decreasing the cellular oxygen supply and increasing the cellular oxygen demand. ${ }^{13}$ In addition, hypocapnia causes systemic arterial vasoconstriction, decreasing global and regional oxygen supply. ${ }^{14,15}$

In the setting of organ injury and critical illness, altered $\mathrm{CO}_{2}$ tension may impact upon outcome, ${ }^{16}$ with hypocapnic alkalosis being associated with adverse effects. ${ }^{13}$ Impaired perfusion of the bowel occurs in many clinical states and may occur in the presence of altered $\mathrm{CO}_{2}$ levels. Thus, the coexistence of hypocapnia and mesenteric IR would be important considerations in critical care, and their combination could result in interactions of significant clinical and mechanistic importance.

We hypothesized that hypocapnia would potentiate the organ injury resulting from IR in the splanchnic circulation. We therefore examined the impact of hypocapnia (produced by HFO) on the development of bowel, hepatic and lung injury, in a rat model of superior mesenteric artery IR.

\section{Methods}

Following Institutional Ethics approval (conforming to the guidelines of the Canadian Council for Animal Care), male Sprague-Dawley rats (400-550 g) were used in all experiments.

\section{Anesthesia and surgical dissection}

General anesthesia was induced with ketamine and xylazine, and maintained with ketamine. Tracheostomy was performed, and pancuronium used for muscle relaxation. The animals were ventilated with HFO (Humming VTM, Senko Medical Instrument Manufacturers, Tokyo, Japan) with the following settings $\left(\mathrm{FIO}_{2} 0.21\right.$, frequency $15 \mathrm{~Hz}$, mean airway pressure $\left.7-10 \mathrm{~cm} \mathrm{H}_{2} \mathrm{O}\right)$. Carbon dioxide $\left(\mathrm{CO}_{2}, 5 \%\right)$ was administered in the inspired gas, because pilot studies established that at these HFO settings, the resultant $\mathrm{PaCO}_{2}$ was approximately $40 \mathrm{mmHg}$. The carotid artery was cannulated for invasive blood pressure monitoring and blood sampling. Stable conditions were obtained, baseline inclusion criteria assessed, and baseline static lung compliance measured.

Arterial blood pressure, airway pressure, and temperature were recorded at baseline and at 40, 120 and 180 min following randomization in each group.

\section{Randomization}

Following documentation of baseline stability and absence of exclusion criteria $\left(\mathrm{PaO}_{2}<65 \mathrm{~mm} \mathrm{Hg}\right.$; $\mathrm{PaCO}_{2}<35$ or $>45 \mathrm{mmHg}$; hemoglobin $<15 \mathrm{~g} \cdot \mathrm{dL}^{-1}$; $\mathrm{pH}<7.36$; peak airway pressure $>7 \mathrm{~cm} \mathrm{H}_{2} \mathrm{O}$ following inflation with $5 \mathrm{~mL}$ inflation volume), the animals were randomized into one of four groups:

- Hypocapnia and superior mesenteric artery ischemia reperfusion injury (Hypocapnia-IR)

- Normocapnia and superior mesenteric artery ischemia reperfusion injury (Normocapnia-IR)

- Hypocapnia and sham laparotomy (HypocapniaSham)

- Normocapnia and sham laparotomy (Normocapnia-Sham)

\section{Experimental outline}

Normocapnia was maintained by leaving the fraction of inspired carbon dioxide $\left(\mathrm{FICO}_{2}\right)$ at $0.05(5 \%)$, and hypocapnia was achieved by changing the $\mathrm{FICO}_{2}$ to $0.00(0 \%)$. Pilot experiments performed previously had established that this resulted in a stable and predicable hypocapnic alkalosis. The same HFO settings were maintained for each of the four groups with or without the addition of inspired $5 \% \mathrm{CO}_{2}$ for the remainder of the experiment.

Animals randomized to IR (normocapnic or hypocapnic) received a standardized abdominal wall incision with clamping of the superior mesenteric artery for $45 \mathrm{~min}$. Collateral arteries (the right gastroepiploic artery and the ileocolic artery) were tied off, to eliminate collateral flow. Following ischemia, 
TABLE Final variables (all groups)

\begin{tabular}{lllll}
\hline & Hypocapnia IR & Normocapnia IR & Hypocapnia Sham & Normocapnia Sham \\
\hline $\mathrm{pH}$ & $7.39 \pm 0.17$ & $7.20 \pm 0.12$ & $7.62 \pm 0.08$ & $7.35 \pm 0.02 * \$$ \\
$\left.\mathrm{PaO}_{2}(\mathrm{mmHg})\right)$ & $97.3 \pm 16.8$ & $98.8 \pm 8.5$ & $88.5 \pm 12.3$ & $99.0 \pm 11.1$ \\
$\mathrm{PaCO}_{2}(\mathrm{mmHg})$ & $17.0 \pm 3.0$ & $41.6 \pm 3.7$ & $17.1 \pm 19$ & $40.8 \pm 0.9 \$$ \\
Lung compliance $\left(\mathrm{mL} \cdot \mathrm{cm}^{-1} \mathrm{H}_{2} 0\right)$ & $0.54 \pm 0.2$ & $0.47 \pm 0.1$ & $0.96 \pm 0.2$ & $0.83 \pm 0.3 *$ \\
Lactate $\left(\mathrm{mmol} \cdot \mathrm{L}^{-1}\right)$ & $6.7 \pm 2.4$ & $6.3 \pm 4.1$ & $4.3 \pm 3.7$ & $2.8 \pm 0.8 *$ \\
\hline
\end{tabular}

Values are expressed as mean $\pm \mathrm{SD}$. IR $=$ ischemia-reperfusion. * IR groups (Hypocapnic and Normocapnic) $>$ Sham groups $($ Hypocapnic and Normocapnic) $P<0.05$. Hypocapnic groups (IR and Sham) $>$ Normocapnic groups (IR and Sham) $P<0.05$.

the clamp was removed and the animal was observed for a further $120 \mathrm{~min}$. The animals that were randomized to a sham laparotomy (normocapnic or hypocapnic) received a standardized abdominal incision only, with no additional intra-abdominal manipulation or dissection, and were observed for the same duration as the mesenteric IR animals.

At the end of the experiment, static lung compliance was measured, and the animals exsanguinated under general anesthesia. Samples of plasma, liver and bowel were retained for analysis. The first $2 \mathrm{~cm}$ of small bowel was examined in each case. There were four indices to determine bowel injury, each with a score of 0 to 4 . The highest score for the most severe injury was 16 and the lowest score for an uninjured sample was 0 (Table A, available as Additional Material at www.cja-jca.org). There were five indices to determine lung injury, each with a score of 0 to 4 . The highest score for the most severe injury was 20 and the lowest score for an uninjured sample was 0 (Table B, available as Additional Material at www.cja-jca.org).

Liver injury was assessed by plasma alanine transaminase (ALT), and lipid peroxidation injury by tissue 8 -isoprostane concentrations in the bowel and liver. 8-Isoprostane was purified and quantified using commercially available affinity columns and an enzyme immunoassay kit (Cayman Chemical, Ann Arbor, MI, USA), according to the manufacturer's instructions. ${ }^{17}$ The lung block was dissected and fixed for histologic analysis.

Additional experiments were carried out to measure intestinal blood flow before and after IR, using a laser-Doppler flowmetry under conditions of normocapnia and hypocapnia. ${ }^{18}$ Rats were conventionally ventilated and baseline mesenteric blood flow was assessed in all animals using laser-Doppler flow probes (Oxyflo, Oxford Optronix, Oxford, UK) which were positioned over the splanchnic arteries on the small bowel, and the intestinal blood flow measured with probes in two separate sites. Animals were then assigned to normocapnia ( $n=4 ; \mathrm{PaCO}_{2} \approx 40 \mathrm{mmHg}$, $\mathrm{FICO}_{2} 0.05, \mathrm{FIO}_{2} 0.5$, balance $\mathrm{N}_{2}$ ) or hypocapnia $(n$ $=4 ; \mathrm{PaCO}_{2} \approx 17 \mathrm{mmHg}, \mathrm{FICO}_{2} 0.00, \mathrm{FIO}_{2} 0.5$, balance $\mathrm{N}_{2}$ ). Mesenteric ischemia was then induced (see above), and maintained for $45 \mathrm{~min}$, and the clamp removed and blood flow assessed following ten minutes of reperfusion. At the end of the experiment, the animals were exsanguinated under general anesthesia. The background signal was determined in exsanguinated animals, and this was used to correct all other in vivo flow signals.

\section{Statistical analysis}

Statistical analysis utilized ANOVA followed, if significant, by post-hoc Student-Newman-Keuls tests. Differences were considered significant when $P<$ 0.05 . Results are expressed as mean \pm standard deviation $(\mathrm{SD})$

\section{Results}

\section{Baseline variables}

Baseline variables were comparable in all four groups (Table C, available as Additional Material at www.cjajca.org). These variables were measured during ventilation with $\mathrm{HFO}$, with $\mathrm{FICO}_{2} 0.05$ producing normocapnia. Twenty-two animals were entered. Two animals failed to meet the baseline criteria and were excluded from the study. The 20 animals $(n=6$ for both laparotomy groups; $n=4$ for both sham groups) that were randomized completed the protocol (survival $100 \%$ ). Once randomized, animals assigned to normocapnia and hypocapnia were ventilated with identical HFO parameters, but with different $\mathrm{FICO}_{2}$. In normocapnic groups, the $\mathrm{FICO}_{2}$ was maintained at 0.05 (5\% $\mathrm{CO}_{2}$ ), yielding comparable mean $\mathrm{PaCO}_{2}$ levels of 40.6 $\pm 1.9 \mathrm{mmHg}$ (Normocapnia-IR) vs $39.5 \pm 1.4 \mathrm{mmHg}$ (Normocapnia-Sham), $(P=0.7)$. In the hypocapnic groups the $\mathrm{FICO}_{2}$ was changed to 0.00 , yielding mean $\mathrm{PaCO}_{2}$ levels of $17.5 \pm 0.9 \mathrm{mmHg}$ (Hypocapnia IR) $p s$ $16.8 \pm 0.7 \mathrm{mmHg}$ (Hypocapnia Sham), $(P=0.6)$. 
Panel A

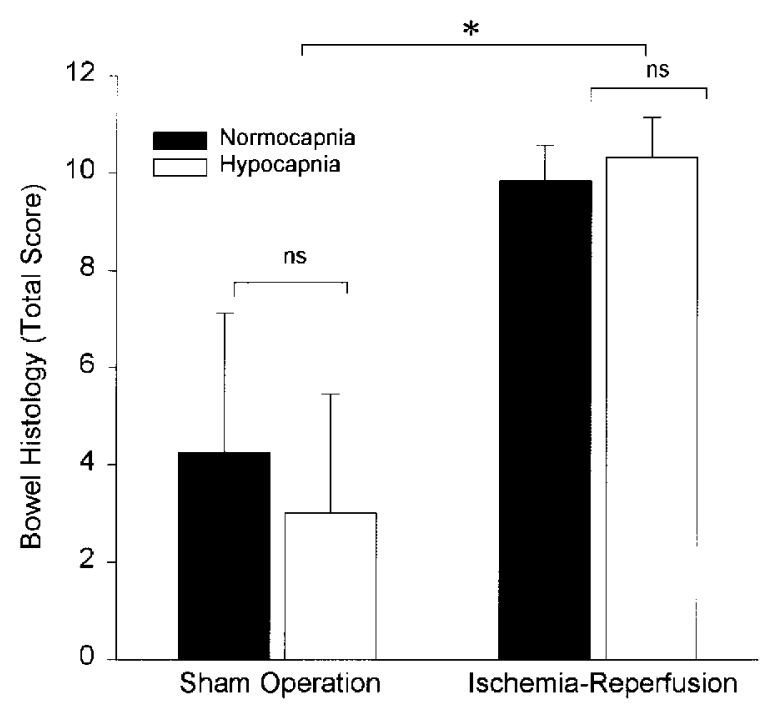

Panel B

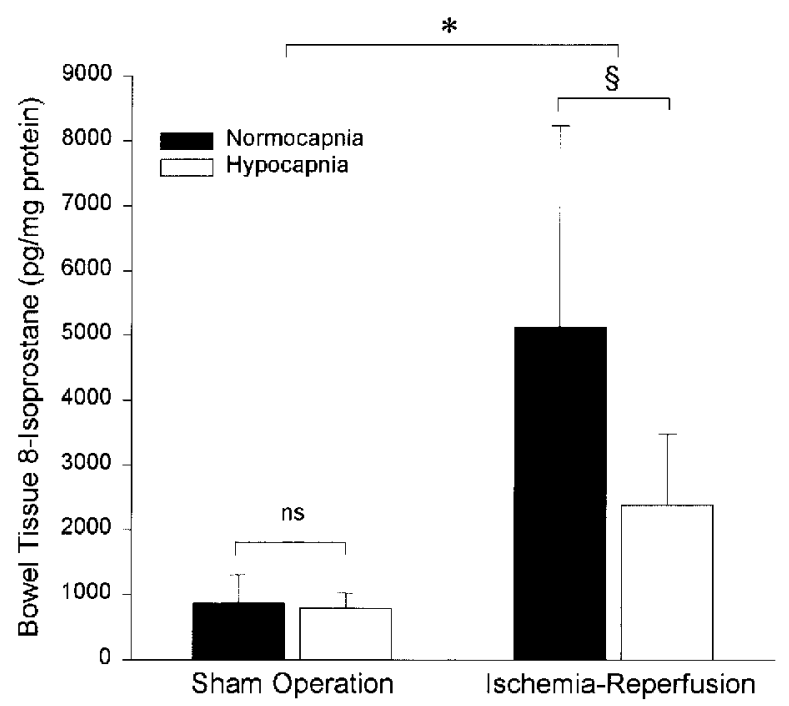

FIGURE 1 Panel A: Bowel histology injury was significantly worse in both ischemia-reperfusion groups (normocapnia and hypocapnia) compared with sham operation groups (normocapnia and hypocapnia); $\left({ }^{*} P<0.05\right)$. Panel B: Bowel tissue 8 -isoprostane was significantly increased in both ischemia-reperfusion groups (normocapnia and hypocapnia) compared with sham operation groups (normocapnia and hypocapnia); $\left({ }^{*} P<0.05\right)$. However the normocapnic ischemia-reperfusion group had a significantly greater increase than the hypocapnic ischemia-reperfusion group $(\$ P<0.05)$.

\section{Bowel injury}

Histological bowel injury ${ }^{19}$ was severe in both IR groups (normocapnia and hypocapnia) $v s$ sham groups (Figure 1A), with no additive effect of hypocapnia. In sham-operated animals, there was no difference in lipid peroxidation (tissue 8 -isoprostane concentration) between the hypocapnia vs normocapnia groups (Figure 1B). IR was associated with higher levels of tissue 8-isoprostane compared with sham experiments, in both normocapnic and hypocapnic groups (Figure 1B). The 8-isoprostane concentration however, was less in the hypocapnic vs normocapnic group following IR.

\section{Hepatic injury}

Global hepatocellular injury, assessed by plasma levels of ALT, occurred in the presence of hypocapnia regardless of whether IR or sham procedure was performed (Figure 2A). Hepatic lipid peroxidation, measured as tissue 8-isoprostane concentration, resulted from mesenteric IR, and was independent of $\mathrm{CO}_{2}$ level (Figure 2B).

\section{Pulmonary effects}

Following superior mesenteric artery IR, final lung compliance was significantly impaired compared with sham operations. This was not altered by normocapnia or hypocapnia (Figure 3A). There was no significant difference in the final $\mathrm{PaO}_{2}$ between the four groups, reflecting maintenance of constant mean airway pressure with HFO (Table). Lung histology ${ }^{20}$ (Table B, available as Additional Material at www.cja-jca.org) was also assessed but there were no changes apparent at the light microscopic level in any of the four groups.

\section{Systemic effects}

Base excess was measured at four time points during the experiment. At the end of the experiment base excess was significantly lower in both IR groups (normocapnic and hypocapnic) compared to sham operated groups (normocapnic and hypocapnic); (Figure 3B), and plasma lactate was significantly higher in both IR groups (normocapnic and hypocapnic) compared to sham operated groups (normocapnic and hypocapnic; Table).

\section{Intestinal blood flow}

Following reperfusion, the blood flow rose to $105.1 \pm$ $13.9 \%$ of baseline flow rate in the normocapnic group, and to $53.8 \pm 10.2 \%$ of baseline flow rate in the hypocapnic group. 
Panel A

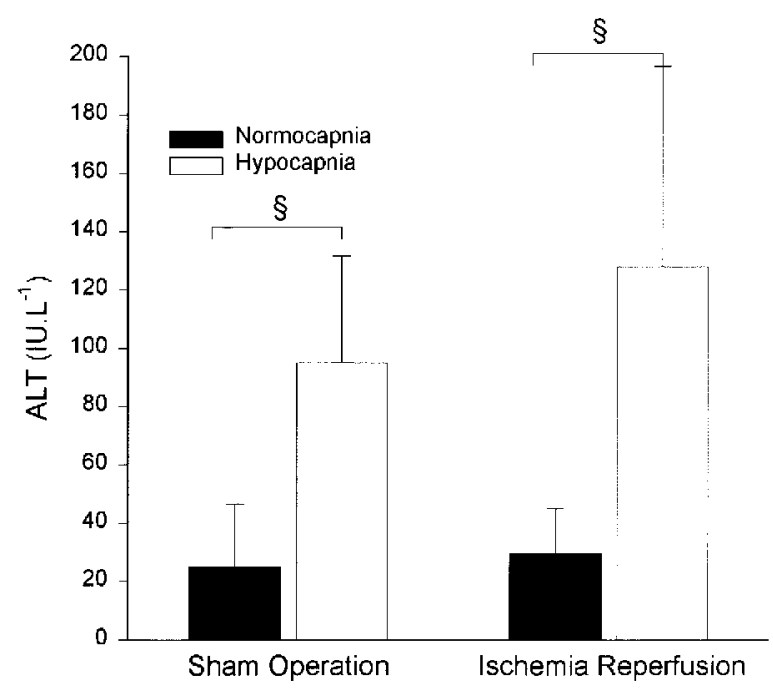

Panel B

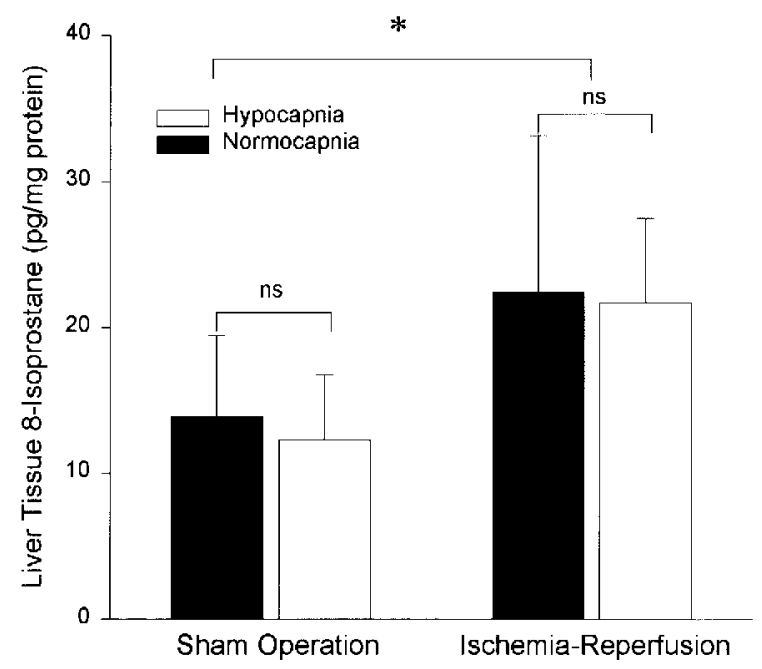

FIGURE 2 Panel A: Hepatic injury was assessed by measuring alanine transaminase (ALT) (IU.L $\mathrm{L}^{-1}$ ). There was a significant increase in ALT in both hypocapnic groups (ischemia-reperfusion and sham operations) compared to the normocapnic groups [ischemia-reperfusion and sham operations; $\$ P<0.05]$. There was no significant difference between the ischemia-reperfusion and sham operation groups. Panel B: Liver tissue 8-isoprostane was significantly increased in both ischemia-reperfusion groups (normocapnia and hypocapnia) compared with sham operation groups (normocapnia and hypocapnia; ${ }^{*} P<0.05$ ).

\section{Discussion}

The principal findings in the current study are that hypocapnia causes hepatic injury under control conditions, but attenuates bowel tissue lipid peroxidation following IR. We further demonstrated that following ischemia, hypocapnia attenuates reperfusion, and suggest that such an inhibition may be responsible for the reduced lipid peroxidation.

\section{Interactions of hypocapnia and mesenteric $I R$}

There are several reasons for concern about the potential interaction between mesenteric ischemia and systemic hypocapnia. First, hypocapnia has been associated with potentiation of ischemic injury in the brain ${ }^{21}$ heart and lung, ${ }^{22}$ and with worsening of edema following ex vivo IR in the lung. ${ }^{23}$ Second, the corollary - that elevated $\mathrm{CO}_{2}$ is protective - has been demonstrated experimentally, where hypercapnia has been associated with protection from IR in several organ systems, including brain ${ }^{21}$ heart and lung. ${ }^{24}$ Third, in terms of gastrointestinal vulnerability, hypocapnia specifically impairs local oxygenation. ${ }^{14}$ Fourth, with increasing utilization of specialized techniques to manage pulmonary or cardiopulmonary failure (e.g., extracorporeal membrane oxygenation,
HFO, high frequency ventilation) especially in pediatric patients, hypocapnia - because it develops so rapidly with these therapies - may become a more prevalent entity. ${ }^{13,25}$

\section{Implications of results}

We found that hypocapnia potentiated the ischemic component and attenuated the reperfusion elements of mesenteric IR injury. We used ALT as a marker of hepatocellular injury ${ }^{26,27}$ and found that this was significantly elevated in the presence of hypocapnia regardless of whether IR or sham operation was performed. We propose that this elevation was secondary to ischemia caused by vasoconstriction as a result of the profound hypocapnia. Others have documented that hypocapnia reduces splanchnic perfusion and causes ischemia, ${ }^{14}$ and our data confirm that hypocapnia reduces reperfusion following mesenteric IR in this model. Hepatic lipid peroxidation, measured as tissue 8-isoprostane concentration, resulted from mesenteric IR, and was independent of $\mathrm{CO}_{2}$ level. The difference may reflect ongoing hepatic artery flow during mesenteric artery occlusion resulting in selective total bowel ischemia but partial hepatic ischemia, as opposed to globally decreased flow in all vascular 
Panel A

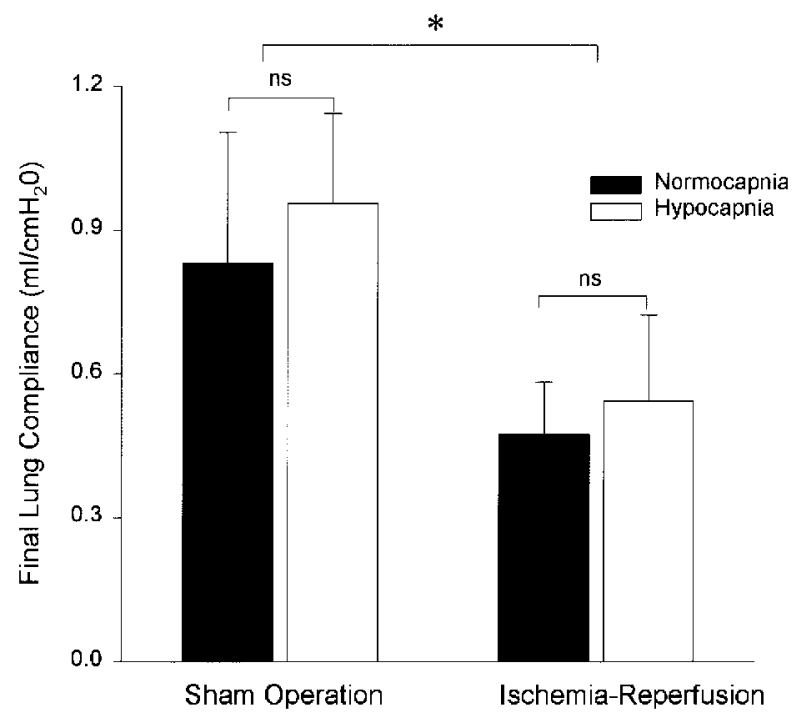

Panel B

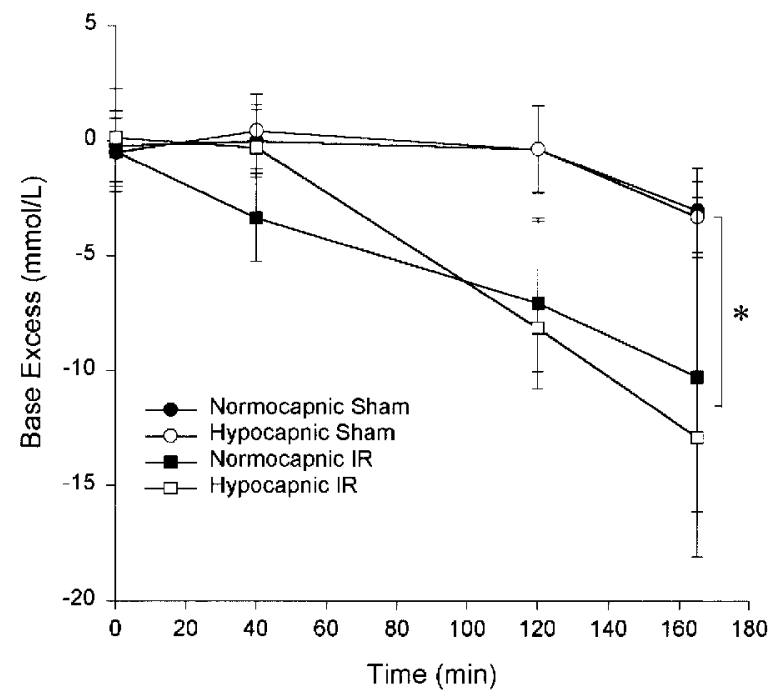

FIGURE 3 Panel A: Final lung compliance $\left(\mathrm{mL} \cdot \mathrm{cm}^{-1} \mathrm{H}_{2} 0\right)$ was significantly impaired in both ischemia-reperfusion groups (normocapnia and hypocapnia) compared with sham operation groups (normocapnia and hypocapnia); $\left({ }^{*} P<0.05\right)$. Panel B: Plasma base excess $\left(\mathrm{mmol} \cdot \mathrm{L}^{-1}\right)$ was measured at four time points: baseline, $40 \mathrm{~min}, 120 \mathrm{~min}$, and $180 \mathrm{~min}$. The decrease in base excess over time was significantly greater in both ischemia-reperfusion groups (normocapnia and hypocapnia) compared with sham operation groups (normocapnia and hypocapnia) at 120 and $180 \mathrm{~min}\left({ }^{*} \mathrm{P}<0.05\right)$.

beds during hypocapnia. The dual hepatic blood supply may therefore explain the differential effects of hypocapnia on lipid peroxidation in the liver.

HFO was used in order to easily obtain hypocapnia without causing stretch-induced lung injury. HFO has been previously found to be protective in animal models of lung injury. ${ }^{28,29}$ Other authors have used HFO in animals of similar size ${ }^{30}$ and because the tidal volumes delivered with HFO represent only a fraction of conventional tidal volumes, its use in the initial series of experiments reduced the potential for concomitant ventilator-induced lung injury.

\section{Limitations of study}

The current study has several limitations that limit extrapolation to the clinical context. First, we utilized a normal lung model which may have diminished the pulmonary effects of IR and hypocapnia. Second, the independent effects of $\mathrm{pH} v \mathrm{~s} \mathrm{CO}_{2}$ were not examined, which is extremely difficult in the in vivo context. Third, the differences of prolonged ischemia $v s$ IR were not studied. Finally severe hypocapnia is uncommon in clinical situations with experienced clinicians and careful monitoring; however, it is certainly possi- ble to develop severe hypocapnia with the institution of extracorporeal membrane oxygenation and HFO in critically ill children or during cardiopulmonary bypass. ${ }^{6-8,25}$

\section{Conclusion}

In this experimental model of superior mesenteric artery IR injury, hypocapnia achieved by HFO ventilation although directly injurious to the liver, attenuated reperfusion bowel injury.

\section{References}

1 Arnold JH, Anas NG, Luckett P, et al. High-frequency oscillatory ventilation in pediatric respiratory failure: a multicenter experience. Crit Care Med 2000; 28 : 3913-9.

2 Courtney SE, Durand DJ, Asselin JM, Hudak ML, Aschner JL, Shoemaker CT. High-frequency oscillatory ventilation versus conventional mechanical ventilation for very-low-birth-weight infants. The Neonatal Ventilation Study Group. N Engl J Med 2002; 347: 643-52.

3 Derdak S, Mehta S, Stewart TE, et al. High-frequency oscillatory ventilation for acute respiratory distress syn- 
drome in adults. A randomized, controlled trial. The Multicenter Oscillatory Ventilation for Acute Respiratory Distress Syndrome Trial (MOAT) Study Investigators. Am J Respir Crit Care Med 2002; 166: 801-8.

4 Berkenbosch JW, Tobias JD. Transcutaneous carbon dioxide monitoring during high-frequency oscillatory ventilation in infants and children. Crit Care Med 2002; 30: 1024-7.

5 Froese $A B$, Bryan AC. High frequency ventilation. Am Rev Respir Dis 1987; 135: 1363-74.

6 Krishnan JA, Brower RG. High-frequency ventilation for acute lung injury and ARDS. Chest 2000; 118 : 795-807.

7 Priebe GP, Arnold JH. High-frequency oscillatory ventilation in pediatric patients. Respir Care Clin N Am 2001; 7: 633-45.

8 Riphagen $S$, Bohn D. High frequency oscillatory ventilation. Intensive Care Med 1999; 25: 1459-62.

9 Grace PA. Ischaemia-reperfusion injury. Br J Surg 1994; 81: 637-47.

10 Carden DL, Granger DN. Pathophysiology of ischaemia-reperfusion injury. J Pathol 2000; 190: 255-66.

11 Nielsen VG, Tan $S$, Weinbroum A, et al. Lung injury after hepatoenteric ischemia-reperfusion: role of xanthine oxidase. Am J Respir Crit Care Med 1996; 154: 1364-9.

12 Starnes HF Jr, Warren RS, Jeevanandam M, et al. Tumor necrosis factor and the acute metabolic response to tissue injury in man. J Clin Invest 1988; 82: $1321-5$.

13 Laffey JG, Kavanagh BP. Hypocapnia. N Engl J Med 2002; 347: 43-53.

14 Guzman JA, Kruse JA. Splanchnic hemodynamics and gut mucosal-arterial $\mathrm{PCO}_{2}$ gradient during systemic hypocapnia. J Appl Physiol 1999; 87: 1102-6.

15 Price HL. Effects of carbon dioxide on the cardiovascular system. Anesthesiology 1960; 21: 652-63.

16 Laffey JG, Kavanagh BP. Carbon dioxide and the critically ill-too little of a good thing? Lancet 1999; 354: 1283-6.

17 Fischer S, Maclean AA, Liu M, Kalirai B, Keshavjee S. Inhibition of angiotensin-converting enzyme by captopril: a novel approach to reduce ischemia-reperfusion injury after lung transplantation. J Thorac Cardiovasc Surg 2000; 120: 573-80.

18 Hare GM, Mazer CD, Mak W, et al. Hemodilutional anemia is associated with increased cedrebral neuronal nitric oxide synthase gene expression. J Appl Physiol 2003; 94: 2058-67.

19 Hammerman C, Goldschmidt D, Caplan MS, et al. Protective effect of bilirubin in ischemia-reperfusion injury in the rat intestine. J Pediatr Gastroenterol Nutr 2002; 35: 344-9.

20 Rimensberger PC, Pristine G, Mullen BM, Cox PN, Slutsky AS. Lung recruitment during small tidal volume ventilation allows minimal positive end-expiratory pressure without augmenting lung injury. Crit Care Med 1999; 27: 1940-5.

21 Vannucci RC, Towfighi J, Heitjan DF, Brucklacher RM. Carbon dioxide protects the perinatal brain from hypoxic-ischemic damage: an experimental study in the immature rat. Pediatrics 1995; 95: 868-74.

22 Shepard JW Jr, Hauer D, Miyai K, Moser KM. Lamellar body depletion in dogs undergoing pulmonary artery occlusion. J Clin Invest 1980; 66: 36-42.

23 Laffey JG, Engelberts D, Kavanagh BP. Injurious effects of hypocapnic alkalosis in the isolated lung. Am J Respir Crit Care Med 2000; 162: 399-405.

24 Laffey JG, Tanaka M, Engelberts D, et al. Therapeutic hypercapnia reduces pulmonary and systemic injury following in vivo lung reperfusion. Am J Respir Crit Care Med 2000; 162: 2287-94.

25 Sussmane JB, Totapally BR, Hultquist K, Torbati D, Wolfsdorf J. Effects of arteriovenous extracorporeal therapy on hemodynamic stability, ventilation, and oxygenation in normal lambs. Crit Care Med 2001; 29: 1972-8.

26 Heijnen BH, Elkhaloufi $\Upsilon$, Straatsburg IH, Van Gulik $T M$. Influence of acidosis and hypoxia on liver ischemia and reperfusion injury in an in vivo rat model. J Appl Physiol 2002; 93: 319-23.

27 Moulin F, Copple BL, Ganey PE, Roth RA. Hepatic and extrahepatic factors critical for liver injury during lipopolysaccharide exposure. Am J Physiol Gastrointest Liver Physiol 2001; 281: G1423-31.

28 von der Hardt K, Kandler MA, Fink L, et al. High frequency oscillatory ventilation suppresses inflammatory response in lung tissue and microdissected alveolar macrophages in surfactant depleted piglets. Pediatr Res 2004; 55: 339-46.

29 van Kaam AH, de Jaegere A, Haitsma JJ, Van Aalderen WM, KokJH, Lachmann B. Positive pressure ventilation with the open lung concept optimizes gas exchange and reduces ventilator-induced lung injury in newborn piglets. Pediatr Res 2003; 53: 245-53.

30 Vazquez de Anda GF, Hartog A, Verbrugge SJ, Gommers D, Lachmann B. The open lung concept: pressure controlled ventilation is as effective as high frequency oscillatory ventilation in improving gas exchange and lung mechanics in surfactant-deficient animals. Intensive Care Med 1999; 25: 990-6. 